\title{
Gangrenous Chickenpox with Atypical Clinical and Histopathological Findings
}

\author{
Leonardo Bianchi $^{\mathrm{a}}$ Stefano Simonetti ${ }^{\mathrm{a}}$ Katharina Hansel ${ }^{\mathrm{a}}$ \\ Franco Baldellib $^{b}$ Elisabetta Schiaroli ${ }^{b}$ Luca Stingeni $^{a}$ \\ ${ }^{a}$ Clinical, Allergological and Venereological Dermatology Section, Department of Medicine, \\ University of Perugia, Perugia, Italy; ${ }^{b}$ Unit of Infectious Diseases, Department of Medicine, \\ University of Perugia, Perugia, Italy
}

\section{Introduction}

Varicella (chickenpox) is a highly contagious disease caused by varicella zoster virus (VZV). The primary infection results in acute varicella with fever, malaise, and a widely disseminated vesicular and itching rash, frequently solving with scars. The rash begins on the face, scalp, and trunk and occurs in crops; typically, lesions are at different stages of evolution. The oral mucous membrane is frequently involved, with small painful ulcers [1]. Histopathology is characterized by intraepidermal blister, acantholysis or necrosis of the epithelium, and lymphoid infiltrates. Infected cells show characteristic viral cytopathic effects with ballooning degeneration, eosinophilic cytoplasmic inclusions, and glassy, eosinophilic, nuclear inclusions with marginated chromatin, often with multiple nuclei [2].

\section{Case History}

A Ghanaian 30-year-old male, living in Italy for 3 weeks, presented with several vesicles with central umbilication and scabs, sometimes with central necrotic eschar, involving the face, trunk, and limbs but not the scalp (Fig. 1a, b). Oral mucosa was undamaged. The skin rash had started 1 week before on the thighs and had spread within 5 days. It was preceded by fever $\left(37.5^{\circ} \mathrm{C}\right)$ and cough 2 weeks before, unsuccessfully treated with amoxicillin and clavulanic acid ( $1 \mathrm{~g}$ b.i.d. for 6 days). Multiple lymphadenopathies were present. The patient denied previous illness, except for malaria that had occurred 10 years before.

Laboratory tests showed absolute monocytosis $(630 / \mathrm{mL} ; 11.5 \%)$ and increased inflammatory markers (erythrocyte sedimentation rate 62, C-reactive protein $5.3 \mathrm{mg} / \mathrm{dL}$ ). Chest 
Bianchi et al.: Gangrenous Chickenpox with Atypical Clinical and Histopathological Findings
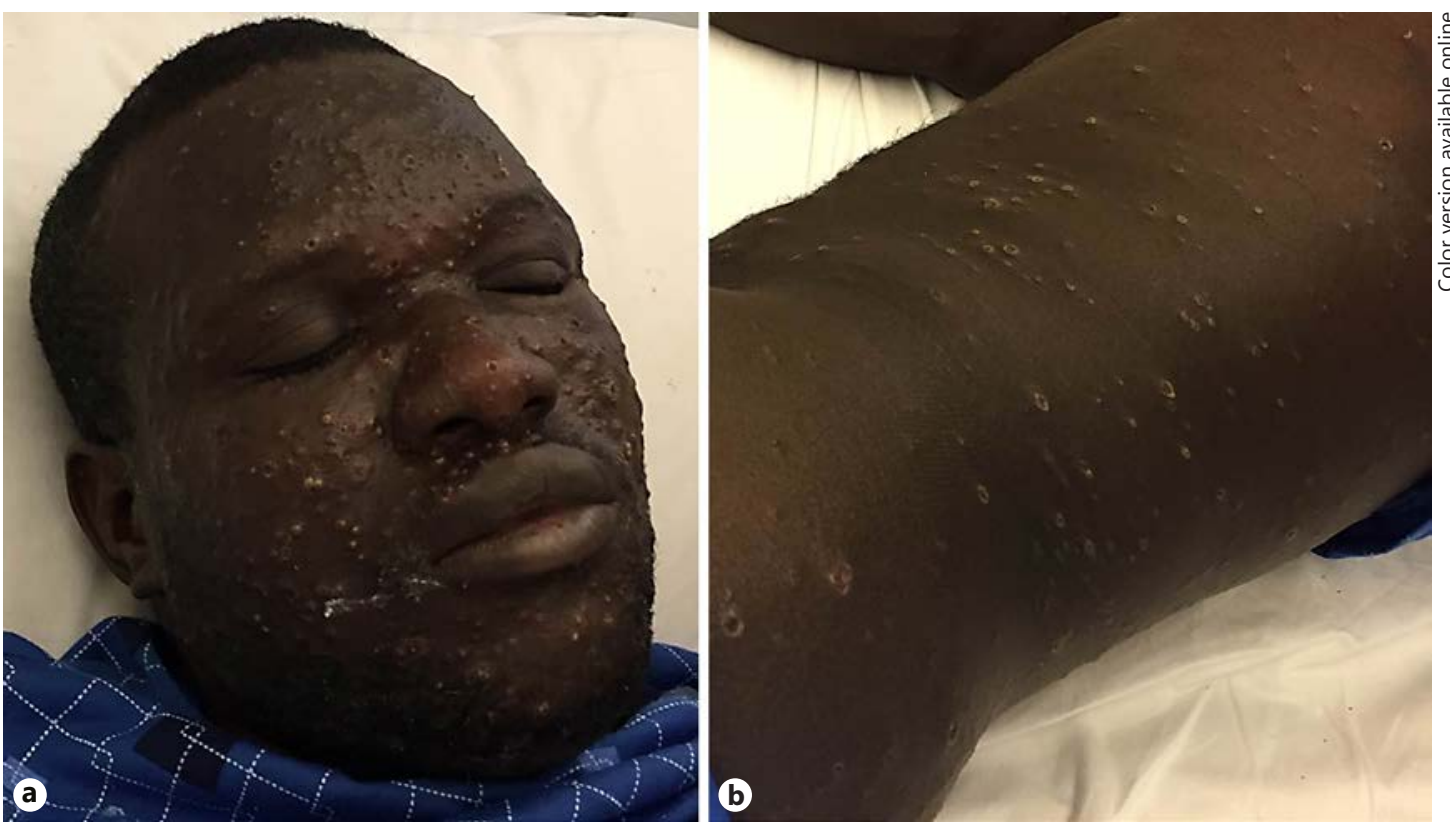

Fig. 1. Skin rash with several vesicles, with central umbilication and scabs, sometimes with central necrotic eschar, involving the face (a), trunk, and arms (b).
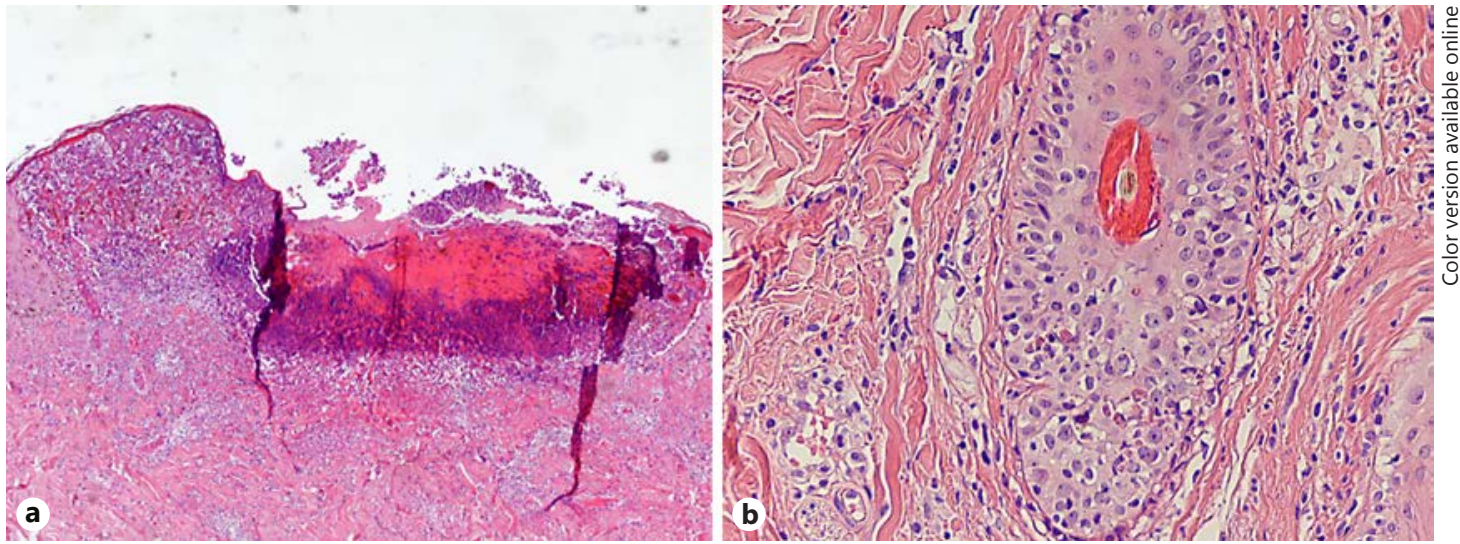

Fig. 2. Skin biopsy revealed massive necrosis at the epidermis and papillary dermis, with peripheral neutrophilic infiltrate (a) and slight aspects of koilocytosis involving keratinocytes located near the necrotic epidermis and on hair follicles in the lower dermis (b).

X-ray was negative. Real-time RT-PCR revealed presence of VZV DNA both in vesicle liquid $(1,816,923$ copies $/ \mathrm{mL})$ and blood $(2,495$ copies/mL). Serology for hepatitis B and C virus, HIV, and syphilis, RT-PCR for monkeypox from blood, SeptiFast, and Quantiferon were negative.

Skin biopsy revealed massive necrosis of the epidermis and papillary dermis, with peripheral neutrophilic infiltrate and slight koilocytosis involving keratinocytes near to necrotic epidermis and hair follicles in the lower dermis (Fig. 2a, b). Immunohistochemical stains showed massive CD3+ lymphocyte infiltrate, both CD4+ and CD8+, and several CD68+ histiocytes. VZV was also isolated in a skin cell culture. 
The patient was treated with acyclovir $750 \mathrm{mg}$ t.i.d. intravenously for 10 days with complete healing within 2 weeks with slight scars. The diagnosis of gangrenous chickenpox with atypical clinical and histopathological findings was performed based on clinical, microbiological, and histopathological findings.

\section{Discussion}

The primary infection with VZV usually occurs with typical clinical features [1]. Nevertheless, atypical lesions (necrotic [3], verrucous [4], and polymorphic light eruption-like [5] lesions) have been described, especially in immunocompromised subjects or patients with hemopathies or undergoing hemodialysis. Our patient presented necrotic synchronous lesions not involving the scalp, resembling monkeypox infection [6]. However, RT-PCR for monkeypox resulted negative, and immunodeficiencies and hemopathies were excluded.

In our case, histopathological findings revealed necrosis and neutrophilic infiltrate, similar to those observed in pityriasis lichenoides et varioliformis acuta (PLEVA) [7], while the typical chickenpox aspects (intraepidermal blister, acantholysis, lymphoid infiltrates, and viral cytopathic effects [2]) were slightly represented. Cases with clinical and histological findings compatible with PLEVA, associated with VZV isolated from blood or skin, are rarely reported in the literature [8-10]. Nevertheless, in our patient, the rapid healing after acyclovir treatment led us to perform a diagnosis of atypical and gangrenous chickenpox.

\section{Statement of Ethics}

The authors have no ethical conflicts to disclose.

\section{Disclosure Statement}

The authors have no conflicts of interest to disclose. There were no funding sources for this work.

\section{References}

1 Ayoade F, Gossman WG: Varicella (Chickenpox), Zoster. StatPearls. Treasure Island, FL, StatPearls Publishing, June 2017 to October 5, 2017. https://www.ncbi.nlm.nih.gov/books/NBK448191/.

-2 Solomon IH, Milner DA Jr: Histopathology of vaccine-preventable diseases. Histopathology 2017;70:109-122.

3 Patterson JW: Weedon's Skin Pathology - Varicella (Chickenpox), ed 4. Churchill Livington, Elsevier, 2016, p 727.

-4 Fagan WA, Collins PC, Pulitzer DR: Verrucous herpes virus infection in human immunodeficiency virus patients. Arch Pathol Lab Med 1996;120:956-958.

5 Osborne GE, Hawk JL: Photodistributed chickenpox mimicking polymorphic light eruption. Br J Dermatol 2000;142:584-585.

6 Sale TA, Melski JW, Stratman EJ: Monkeypox: an epidemiologic and clinical comparison of African and US disease. J Am Acad Dermatol 2006;55:478-481.

7 Fernandes NF, Rozdeba PJ, Schwartz RA, Kihiczak G, Lambert WC: Pityriasis lichenoides et varioliformis acuta: a disease spectrum. Int J Dermatol 2010;49:257-261.

-8 Boralevi F, Cotto E, Baysse L, Jouvencel C, Léauté-Labréze C, Taïeb A: Is varicella-zoster virus involved in the etiopathogeny of pityriasis lichenoides? J Invest Dermatol 2003;121:647-648.

\9 Hervás JA, Martín-Santiago A, Hervás D, Gómez C, Dueñas J, Reina J: Varicella precipitating febrile ulceronecrotic Mucha-Habermann disease. Pediatr Dermatol 2013;6:e216-e217.

10 Cho E, Jun HJ, Cho SH, Lee JD: Varicella-zoster virus as a possible cause of pityriasis lichenoides et varioliformis acuta. Pediatr Dermatol 2014;31:259-260. 